\title{
Where should bulking agents for female urodynamic stress incontinence be injected?
}

\author{
Annette Kuhn • Werner Stadlmayr • \\ Daniela Lengsfeld • Michel D. Mueller
}

Received: 7 November 2007 / Accepted: 29 November 2007 /Published online: 21 December 2007

(C) International Urogynecology Journal 2007

\begin{abstract}
For bulking agents used for female stress urinary incontinence, the recommendation for the anatomical placement varies as some injectables are to be placed close to the bladder neck and others midurethrally. Aim of the study was to determine if there are differences concerning the outcome after transurethral collagen injections depending on the anatomical placement midurethrally or at the bladder neck. We randomly assigned 30 elderly female patients with urodynamic stress incontinence to either transurethral collagen injection midurethrally or to the bladder neck. Prior to injection and at ten month follow-up, maximum urethral closure pressure (MUCP), functional urethral length (FUL), maximum flow rate and cough test were performed and the patient was asked to estimate her bladder condition using a visual analogue scale. Postoperative contentness was 8 (median, 95\% confidence interval $5-9$ ) in the midurethral group and 8 (median, 95\% confidence interval 7-10) in the bladder neck group with a $\mathrm{p}$ value of $0.012,95 \%$ confidence interval -2.464 to -0.2859 , in favour to midurethral injections. MUCP and FUL increased significantly in both groups and flow rate decreased in both groups. Continence was $66.6 \%$ in the midurethral group and $60 \%$ for the bladder neck group respectively. Both midurethral and bladder neck collagen injections improve patients' satisfaction almost equally with a small advantage for midurethral injections.
\end{abstract}

\footnotetext{
A. Kuhn · W. Stadlmayr · D. Lengsfeld • M. D. Mueller Frauenklinik,

Inselspital Bern, Switzerland

A. Kuhn $(\bowtie)$

Department of Urogynaecology, Frauenklinik,

Effingerstr.102,

CH 3010 Bern, Switzerland

e-mail: annette.kuhn@insel.ch
}

Keywords Bulking agents · Placement . Urodynamic stress incontinence

\section{Introduction}

If conservative management has failed, bladder neck injections are the most minimal invasive therapy for urinary stress incontinence. According to a recent systematic review from the Cochrane Database [1], injection therapy may represent a useful option for short-term symptomatic relief amongst selected women with comorbidity that precludes anaesthesia.

Bladder neck injections have a low complication rate. Peri-urethral injectable agents have been used for the treatment of urinary incontinence in women for the past century. A variety of substances have been reported in the peer reviewed literature including bovine glutaraldehyde cross-linked (GAX) collagen, polytetrafluoroethylene (Teflon), polydimethyl-siloxane elastomer (silicone), carboncoated zirconium beads, hyaluronic acid/dextranomer and autologous tissues as fat and cartilage [1-5]. Collagen is one of the best-documented substances [6-12]; however, long-term success rates are not satisfactory [13]. Initially, Teflon injections were applied, but the course of time showed migration and complications and this material has now been abandoned [14].

Success rates range from 26 to $75 \%$, and this procedure is generally not considered that effective.

Historically, the bladder neck used to be the anatomic area to be addressed using surgery for stress incontinence: Burch colposuspension and abdominal sling procedures will lift the bladder neck by elevation of the bladder neck $[15,16]$. Newer techniques place artificial suburethral slings under the mid-urethra [17] based on the "integral 
Table 1 Satisfaction and urodynamics

\begin{tabular}{|c|c|c|c|c|}
\hline & $\begin{array}{l}\text { Bladder neck } \\
\text { preoperative }\end{array}$ & $\begin{array}{l}\text { Bladder neck } \\
\text { postoperative }\end{array}$ & $\begin{array}{l}\text { Mid-urethral } \\
\text { preoperative }\end{array}$ & $\begin{array}{l}\text { Mid-urethral } \\
\text { postoperative }\end{array}$ \\
\hline $\begin{array}{l}\text { Satisfaction } \\
\text { (VAS, mean) }\end{array}$ & 3.8 & 7.2 & 4 & 8.2 \\
\hline MUCP (cm $\mathrm{H}_{2} \mathrm{O}$, mean) & 20.7 & 41.9 & 23.6 & 27.1 \\
\hline $\begin{array}{l}\text { Maximum flow rate } \\
(\mathrm{ml} / \mathrm{s}, \text { mean })\end{array}$ & 24.3 & 17.3 & 28.8 & 16.06 \\
\hline $\begin{array}{l}\text { Functional urethral } \\
\text { length (mm, mean) }\end{array}$ & 23.2 & 25.1 & 20.6 & 30.7 \\
\hline Positive cough test $(n)$ & 15 & 6 & 15 & 5 \\
\hline
\end{tabular}

theory" presented by Petros and Ulmsten [18]. In their "integral theory" impairment of the pubo-urethral ligaments is one of the primary causes of stress urinary incontinence. The authors conclude that to compensate for the insufficiency of the pubo-urethral ligaments, a narrow strip of polypropylene is placed at the point of maximal urethral closure pressure at the mid-urethra.

For bulking agents, the recommendation for the anatomical placement varies, as some injectables are to be placed close to the bladder neck and others mid-urethrally [19, 20].

The aim of the study was to determine if there are differences concerning the outcome after transurethral collagen injections for urodynamic stress incontinence depending on the anatomical placement mid-urethrally or at the bladder neck.

\section{Materials and methods}

The study was performed in the Department of Gynaecology, Frauenklinik, Inselspital Berne, Switzerland.

Between December 2004 and April 2006, we randomly assigned elderly female patients with urodynamic stress incontinence to either collagen injection mid-urethrally or to the bladder neck. Randomisation was computer-assisted, and all patients gave written and oral consent to the study. At least 4 weeks before injection, an intradermal collagen allergy test was performed using $0.1 \mathrm{ml}$ Contigen ${ }^{\circledR}$ being injected into the left forearm.

Urodynamic investigations were done before surgery. Cystometry was performed in the sitting position with the patient in the $45^{\circ}$ upright position with a 6-French microtip transducer which was introduced into the bladder for intravesical pressure measurement, and a water-perfused balloon catheter was introduced into the rectum for intraabdominal pressure measurement. Bladder was filled with a rate of $20 \mathrm{ml} / \mathrm{min}$ with saline solution at $37^{\circ}$. Filling was continued until the patient experienced a strong desire to void. A cough stress test was performed every hundred millilitres of filling. At bladder capacity pressure, flow studies were performed. Urethra pressure profile was performed at rest three times repetitively, and the maximum urethra closing pressure (MUCP) and functional urethral length were measured.

The patients were blinded to the group assignment. Due to a different injection technique, the surgeon (AK) was not blinded to the group assignment.

Before injection, a urinary tract infection was excluded, and all patients received perioperatively sulfamethoxazol commencing immediately before injection.

Injections were performed in operating theatre with the patient in lithotomy position using a Wolf ${ }^{\circledR}$ transurethral cystoscope with working channel and a 7-French injection needle with shoulder. With this type of cystoscope (Wolf ${ }^{\circledR}$ registered number 8252.041 ) and $25^{\circ}$ optic, the injection of bulking material is particularly easy, as it can be operated single-handedly and is originally designed for this operation.

Depth of injection was defined by the shoulder of the injection needle which is $8 \mathrm{~mm}$ long. The needle was inserted until the shoulder reached urethral level in all patients.

Urethral length was measured before injection using a transurethral catheter with a blocked intravesical balloon, which was marked with a permanent marker at the level of

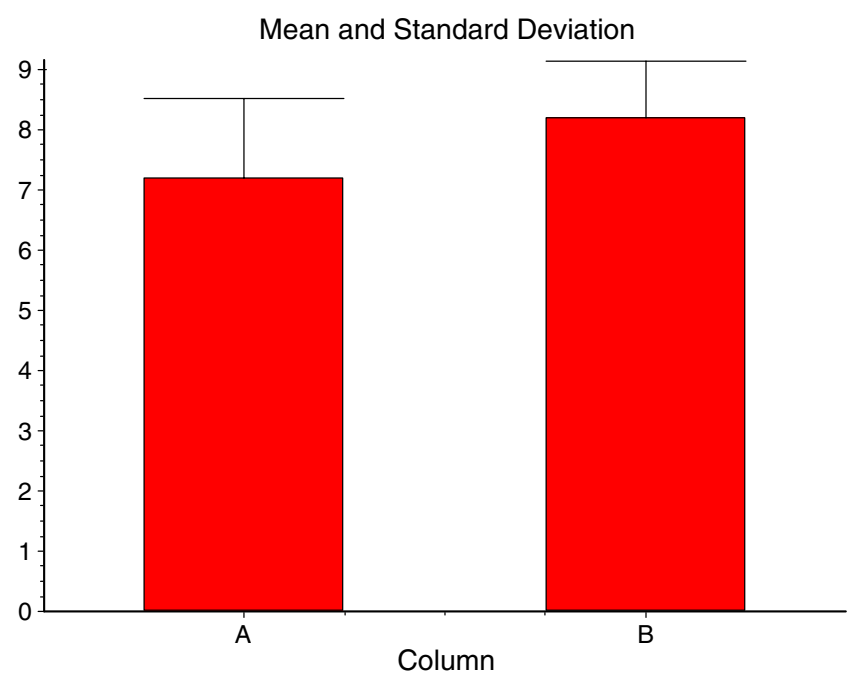

Fig. 1 Postoperative patients' satisfaction: $A$ bladder neck injections, $B$ mid-urethral injection 


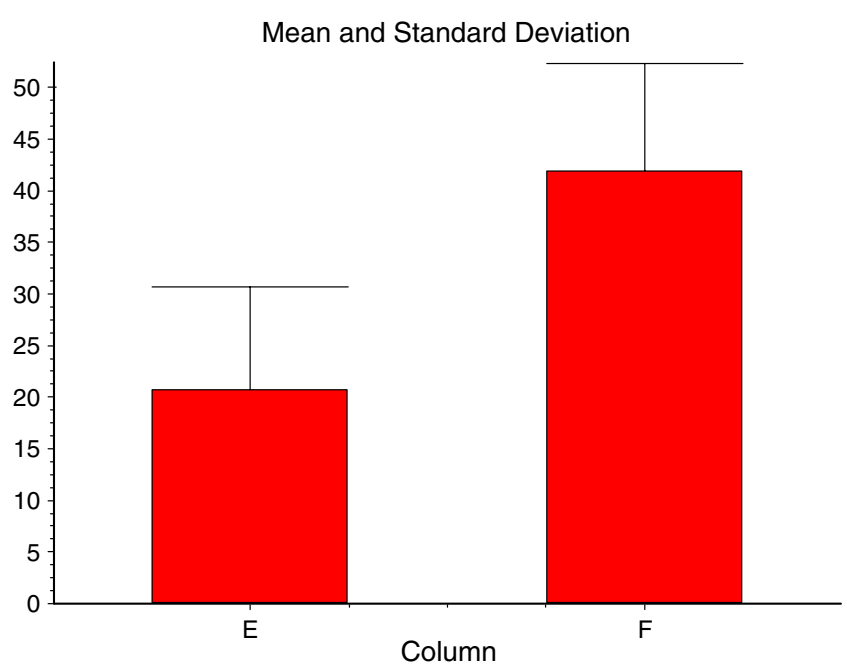

Fig. 2 Mid-urethral injection: MUCP pre- $(E)$ and postoperative $(F)$

the external urethral meatus, then was withdrawn and the distance to mid-urethra calculated dividing urethral length by 2 for the mid-urethral group and the complete length for the bladder neck group subtracting $5 \mathrm{~mm}$.

In both groups, the desired distance was marked on the cystoscope, the cystoscope was inserted until the mark was reached, and Contigen ${ }^{\circledR}$ (Bard) was injected under visual control until coaptation was reached. The injected material and estimated leakage of material was noted. The procedure was performed under local para-urethral anaesthetic with $2 \%$ lignocaine and intra-urethral lidocaine jelly.

Postoperatively, residual urine was measured using trans-abdominal ultrasound, and residual urine was considered insignificant when it was less then $100 \mathrm{ml}$. The patient was then discharged. Follow-up took place after 6 weeks and 10 months and included patient satisfaction using a visual analogue scale (VAS) with the least satisfaction

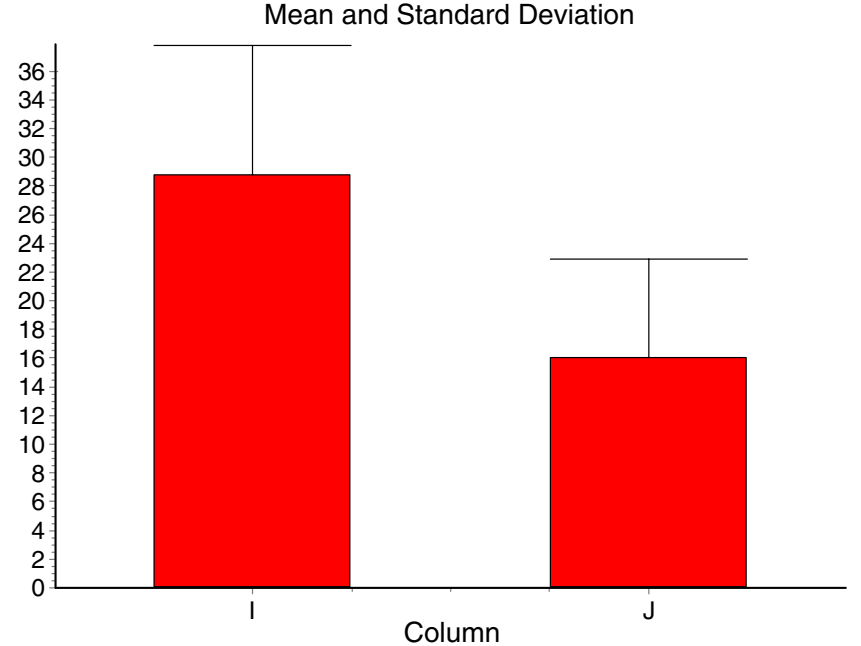

Fig. 4 Mid-urethral injection: Flow pre- $(I)$ and postoperatively $(J)$

being a 0 and the most satisfaction being a 10 . Rate of $0-3$ was considered not satisfied, 4-7 moderately satisfied and more than 8 as satisfied. The exact wording to determine satisfaction was "How satisfied are you with the current bladder condition?"

Residual urine was measured using ultrasound, urethral resting pressure and functional urethral length; cough test at bladder capacity and flowmetry were performed as well. Cough test was noted positive when any leakage could be detected.

Statistics were performed using the InStat system version 4.0 for windows.

We calculated a power of $80 \%$ with a significance level $\alpha=0.05$ and the assumption of the true difference between means of 3 on VAS if we had 15 patients in each group. The expected standard deviation was assumed 3 because of our classification of contentment.

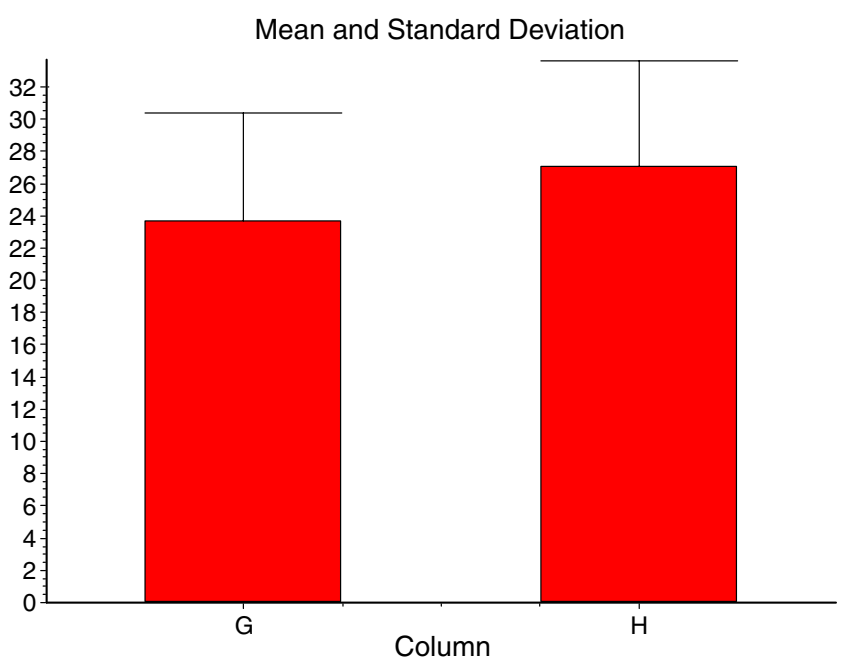

Fig. 3 Bladder neck injection: MUCP pre- $(G)$ and postoperative $(H)$

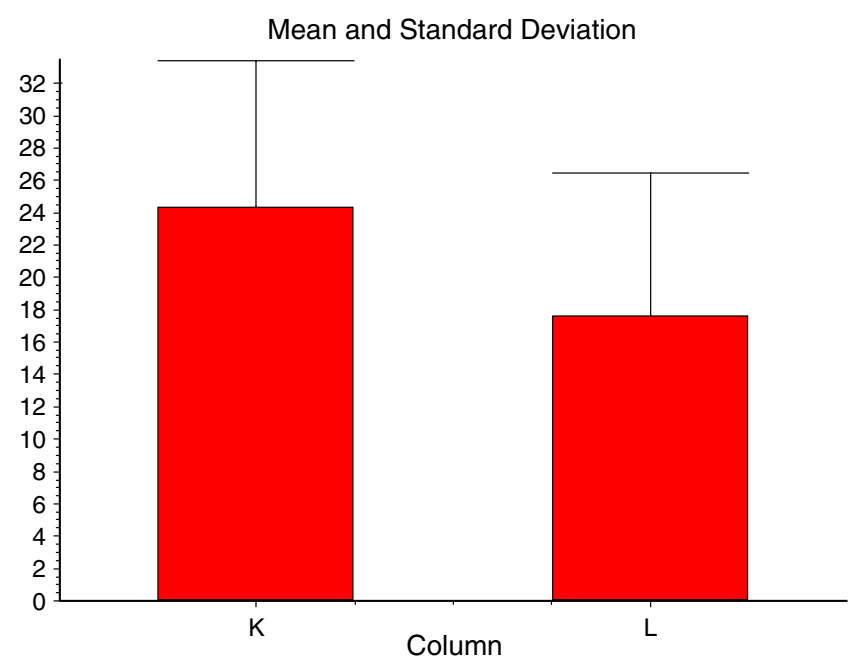

Fig. 5 Bladder neck injection: Flow pre- $(K)$ and postoperatively $(L)$ 


\section{Results}

Thirty patients participated in this study.

Patients in the bladder neck group were 77.5 years old (median; range 62-92), had a body mass index (BMI) of 27 (median; range 19-33) and had a parity of 2 (median; range 0-3). Patients in the mid-urethral group were aged 68 (median; range 48-89), had a BMI of 27 (median; range 21-34) and had a parity of 2 (median; range 1-3).

Both patient groups did not differ significantly concerning age $(p=0.8493)$, BMI $(p>0.9999)$ or parity.

Table 1 describes patients' satisfaction and urodynamic results pre- and postoperatively.

Postoperative satisfaction was 8 (median, 95\% confidence interval 5-9) in the mid-urethral group and 8 (median, $95 \%$ confidence interval 7-10) in the bladder neck group with a $p$ value of $0.012,95 \%$ confidence interval -2.464 to -0.2859 in favour to mid-urethral injections (Fig. 1).

After mid-urethral injection, maximal urethral closure pressure (MUCP) increased significantly postoperatively $(p<0.0001,95 \%$ confidence interval -26.074 to 16.326 ; Fig. 2).

After bladder neck injection, MUCP increased significantly postoperatively ( $p=0.0003,95 \%$ confidence interval -5.032 to 1.768 ; Fig. 3 ).

Maximum flow rate decreased significantly postoperatively after mid-urethral injection $(p=0.0001,95 \%$ confidence interval 7.13-18.336; Fig. 4).

In addition, after bladder neck injections, maximum flow rate decreased significantly postoperatively $(p=0.0002$, 95\% confidence interval 3.625 to 9.841 ; Fig. 5).

Postoperative acute retention occurred in four women of the mid-urethral group and in none of the bladder neck group. Retention lasted for 24 to $48 \mathrm{~h}$, and urine was drained by intermittent catheterization using eight Charriere catheters.

No patient suffered from urinary tract infection postoperatively.

\section{Discussion}

The current study proves that transurethral collagen injections for female stress urinary incontinence improve significantly the patients' satisfaction and their continence.

However, we were unable to show a clear superiority of either of the techniques, which may also be due to the small sample size.

The success rates with $66.6 \%$ being dry on follow-up in the mid-urethral group and $60 \%$ in the mid-urethral group, respectively, correspond with the literature [7, 8] and are very similar compared with each other. Possibly, the shortness of the female urethra and the "traveling" [13] of the collagen make it difficult to distinguish between bladder neck and mid-urethral placement.

Ideally, the anatomical placement of bulking agents is between the vascular sub-endothelial layer and the muscular layer that allows travelling of the substance between layers and allows coaptation [13]. An anatomical study of the female urethra showed the absence of a well-defined sphincteric structure in the bladder neck region, whereas the majority of thick rhabdomyosphincter fibres could be detected in the middle and caudal thirds of the urethra [21]. We wonder if this structural difference might be the reason for the difference in postoperative retention of four women in the mid-urethral group vs none in the bladder neck group. The mid-urethral injection into the rhabdomyosphincter has possibly bulked the sphincter itself, resulting in postoperative retention, whereas during bladder neck injections, the injectable "disappeared" into connective tissue and the smooth muscle which is described in that study as being rather delicate [21]. To be certain where the collagen went, we would have had to use imaging techniques which we did not [22]. By using our standard injection technique with the needle shoulder as measurement for depth, we cannot be definitely certain to inject into the correct layer, but from our experience with permanent bulking materials (ethylene vinyl alcohol), we know from animal studies that we are sub-endothelially in $90 \%$ of cases (BardC), Data on file).

A weakness of the study is that the surgeon could not be blinded to the technique, but a different team followed patients up. However, this team had the opportunity to check operating notes and could have found out about the technique, which may add bias to the study.

Another weakness of this study is short follow-up and the rather small number of patients. We know from other studies that collagen is disappearing due to collagenase activity and that $26 \%$ only are still continent after 5 years of treatment [14]. The only difference in data between the mid-urethral and the bladder neck group was obvious looking at patients' contentment which was statistically significant in favour to mid-urethral injections. However, statistically significant does not always mean clinically significant.

In conclusion, we may say that both mid-urethral and bladder neck collagen injections improve patients' satisfaction almost equally, with a small advantage for mid-urethral injections.

Conflicts of interest None.

\section{References}

1. Keegan P, Atiemo K, Cody J, McClinton S, Pickard R (2007) Periurethral injection therapy for urinary incontinence in women Cochrane Database systematic Rev 18 (3):CD003881 
2. Barranger E (2003) Results of transurethral injection of silicone micro-implants for female $\mathrm{s}$ with intrinsic sphincter deficiency. $\mathrm{J}$ Urol 164(5):1619-1622

3. Chrouser KL et al (2004) Carbon coated zirconium beads in beta-glucan gel and bovine glutaraldehyde cross-linked collagen injections for intrinsic sphincter deficiency: continence and satisfaction after extended follow up. J Urol 171:11521155

4. Bent AE et al (2001) Treatment of intrinsic sphincter deficiency using autologous ear chondrocytes as a bulking agent. Neurourol Urodyn 20(2):157-165

5. Haab F, Zimmern PE, Leach GE (1997) Urinary stress incontinence due to intrinsic sphincter deficiency: experience with fat and collagen periurethral injections. J Urol 157(4):12831286

6. van Kerrebroeck P et al (2004) Efficacy and safety of a novel system (NASH/Dx copolymer via the implant device) for the treatment of SUI. Urol 64(2):276-281

7. Monga AK, Robinson D, Stanton SL (1995) Periurethral collagen injections for genuine stress incontinence: a 2 year follow up. Br J Urol 75:156

8. Richardson TD, Kennelly MJ, Faerber GJ (1995) Endoscopic injection of glutaraldehyde cross linked collagen for the treatment of intrinsic sphincter deficiency in women. Urology 46(3):378381

9. Pickard R (2003) Periurethral injection therapy for urinary stress incontinence in women Cochrane database syst review (2):CD 003881

10. Monga AK, Stanton SL (1997) Urodynamics - prediction, outcome and analysis of mechanism for cure of stress incontinence by periurethral collagen. Br J Obstet Gynaecol 104:158-162

11. McGuire EJ, English SF (1997) Periurethral collagen injection for male and female sphincteric incontinence: indications, techniques and result. World J Urol 15(5):306-309
12. McGuire E, Appell RA (1994) Transurethral collagen injection for urinary incontinence. Urology 43(4):413-415

13. Kim YH, Kattan MW, Boone TB (1997) Correlation of urodynamic results and urethral coaptation with success after transurethral collagen injection. Urology 50(6):941-948

14. Gorton E, Stanton S, Monga A, Wiskind AK, Lentz GM, Bland DR (1999) Periurethral collagen injection: a long term follow up study. BJU Int 84(9):966-971

15. MacKinney CD, Gaffey MJ, Gillenwater JY (1999) Bladder outlet obstruction after multiple periurethral polytetrafluoroethylene injections. J Urol 153(1):149-151

16. Albo ME, Richter HE, Brubaker L, Norton P, Kraus SR et al (2007) Burch colposuspension versus fascial sling to reduce urinary stress incontinence. N Engl J Med 356(21):2143-255

17. Burch JC (1961) Urethrovaginal fixation to Cooper's ligament for correction of stress incontinence, cystocele and prolapse. Am J Obstet Gynecol 81:281-290

18. Ulmsten U, Henriksson L, Johnson P, Varhos G (1996) An ambulatory surgical procedure under local anaesthesia for treatment of female urinary incontinence. Int Urogynecol J Pelvic Floor Dysfunct $7(2): 81-85$

19. Petros PE, Ulmsten UI (1990) An integral theory of female stress urinary incontinence. Experimental and clinical considerations. Acta Obstet Gynecol Scand Suppl 153:7-31

20. Hagemeier T, Blau U, Gauruder-Burmester A, Tunn R (2006) Paraurethral abscess developing after midurethral Zuidex-injection in women with stress urinary incontinence. Zentralbl Gynakol 128 (2):68-70

21. Colleselli K, Stenzl A, Eder R, Strasser H, Poisel S, Bartsch G (1998) The female urethral sphincter: a morphological and topographical study. J Urol 160(1):49-54

22. Rivas Da, Chancellor MB, Liu J-B, Hanau C Bagley DH, Goldberg B (1996) Endoluminal ultrasonographic and histologic evaluation of periurethral collagen injection. J Endourol 10(1):61-66 